
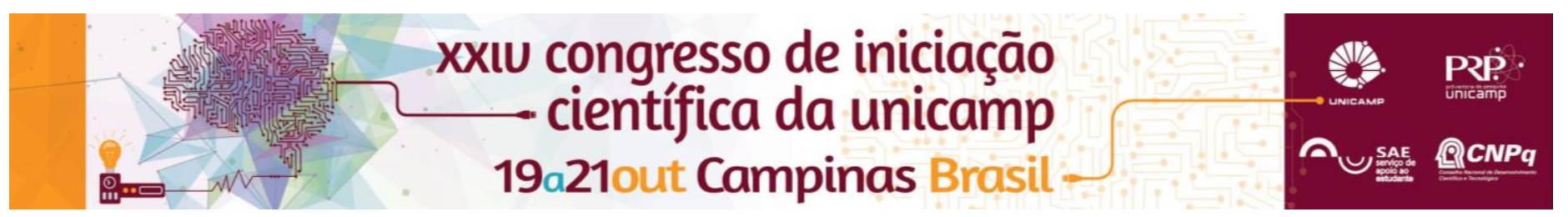

\title{
Maquete física como ferramenta exploratória em projeto arquitetônico - estudo de caso.
}

\author{
Letícia Cavalheiro Martins*, Mayla Magaieski Graepp, Hândrya Daniella Corrêa de Oliveira, Reicia Deucher \\ Nunes, , Prof. Dr. Rogério Teixeira da Silva (orientador)/UNASP-EC.
}

\begin{abstract}
Resumo
Como aspectos fundamentais para o aprendizado na área do conhecimento em Arquitetura e Urbanismo, destacam-se o estudo da forma, a percepção visual das dimensões do espaço e a noção relativa à escala humana como referência, seja em realidade ou em representação, dentre outras questões. Neste sentido, as maquetes físicas se apresentam como importantes ferramentas de estudo, pois, além de permitirem a exploração de ideias estruturais, possibilitam a observação da forma e do espaço físico tridimensional, concretamente. Assim, este trabalho é um estudo de caso, que busca por em prática a confecção de uma maquete arquitetônica como ferramenta de exploração das ideias do arquiteto John Lautner, em um de seus projetos de maior repercussão na década de 60, em Los Angeles/Califórnia - The Chemosphere House.
\end{abstract}

\section{Palavras-chave}

maquetes físicas de estudo, representação tridimensional, arquitetura e urbanismo.

\section{Introdução}

O grande arquiteto brasileiro Paulo Mendes da Rocha faz suas próprias maquetes. Em seu livro Maquetes de Papel, comenta sobre a importância do momento em que constrói os modelos de papel como recurso para aferir suas proposições. Conforme Mendes da Rocha (2007) a maquete facilita o estudo dos volumes, das proporções, das transparências e sombras. Esses modelos permitem o ensaio das virtudes relativas às hipóteses do arquiteto em seus projetos.

Para Ching (2014) o espaço constantemente engloba o nosso ser. Sua forma visual, suas dimensões e escala, o tipo de sua luz - todas essas características dependem de nossa percepção dos limites espaciais definidos pelos elementos da forma. A medida que o espaço começa e ser apreendido, fechado, modelado e organizado pelos elementos da massa, a arquitetura começa a surgir.

Neufert (2014) explica que o homem não se constitui apenas de corpo material que necessita de espaço. A parte relativa às sensações não é de menor importância. Como um local é dimensionado, dividido, pintado, iluminado, mobiliado, é fundamental para a impressão causada em quem ocupa.

Através de um estudo de caso (o projeto do arquiteto John Lautner, conhecido por The Chemosphere House - figuras 1 e 2), foi confeccionada uma maquete como ferramenta de descoberta, isto é, para o estudo exploratório da forma e do espaço, além dos volumes, proporções, sombras e transparências - como elementos vitais preconcebidos pelo arquiteto em sua obra.

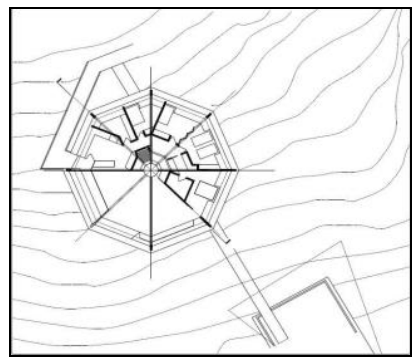

Figura 1. Vista de topo da referência (sem escala)

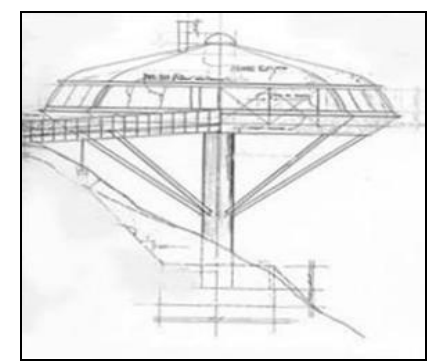

Figura 2. Elevação lateral da referência (sem escala)

\section{Resultados e Discussão}

O trabalho resultou em uma maquete confeccionada com materiais normalmente empregados para tal finalidade, com destaque para o papel, papelão, isopor, acetato e balsa (Figura 3). Através dessa maquete foi possível conferir algumas soluções de projeto, principalmente em relação ao terreno com $45^{\circ}$ de inclinação, além da engenhosidade de se equilibrar uma casa de $200 \mathrm{~m}^{2}$ inteiramente fora do solo sobre um pilar único de $15 \mathrm{~m}$ de altura. Foi possível explorar detalhes construtivos do projeto, com planta octogonal e corte losangular, além das paredes externas que não são de alvenaria, mas composta por oito painéis panorâmicos com excelente vista de Hollywood (Figura 4).

Como resultado deste estudo de caso, percebeuse as seguintes características de projeto - volume sólido primário: esfera; transformação da forma: subtrativa; sistema de organização espacial: radial; circulação: horizontal. Como princípios de ordem foram observados a presença de: eixo radial, ritmo, repetição, simetria, leveza, dinâmica e serenidade (disposição horizontal alongada), agilidade e centralidade.

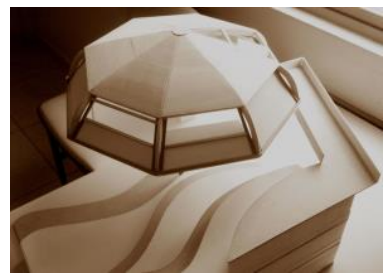

Figura 3. Maquete de estudo (perspectiva)

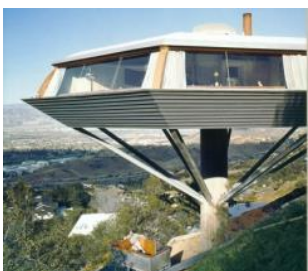

Figura 4. Projeto real (perspectiva)

\section{Conclusões}

A aplicação da maquete como ferramenta de investigação de projeto cumpriu com seu propósito, subsidiando o aprendizado relativo às ideias e soluções de projeto adotadas pelo arquiteto em sua obra.

CHING, Francis DK. Architecture: Form, space, and order. John Wiley \& Sons, 2014.

MENDES DA ROCHA, Paulo. Maquetes de papel. Cosac Naify, São Paulo, 2007

NEUFERT, Ernst. Arte de projetar em arquitetura. G Gili, São Paulo, 2013. 